\title{
Evaluating mine-waste seepage water and solute sources using stable isotopes and inverse geochemical modeling
}

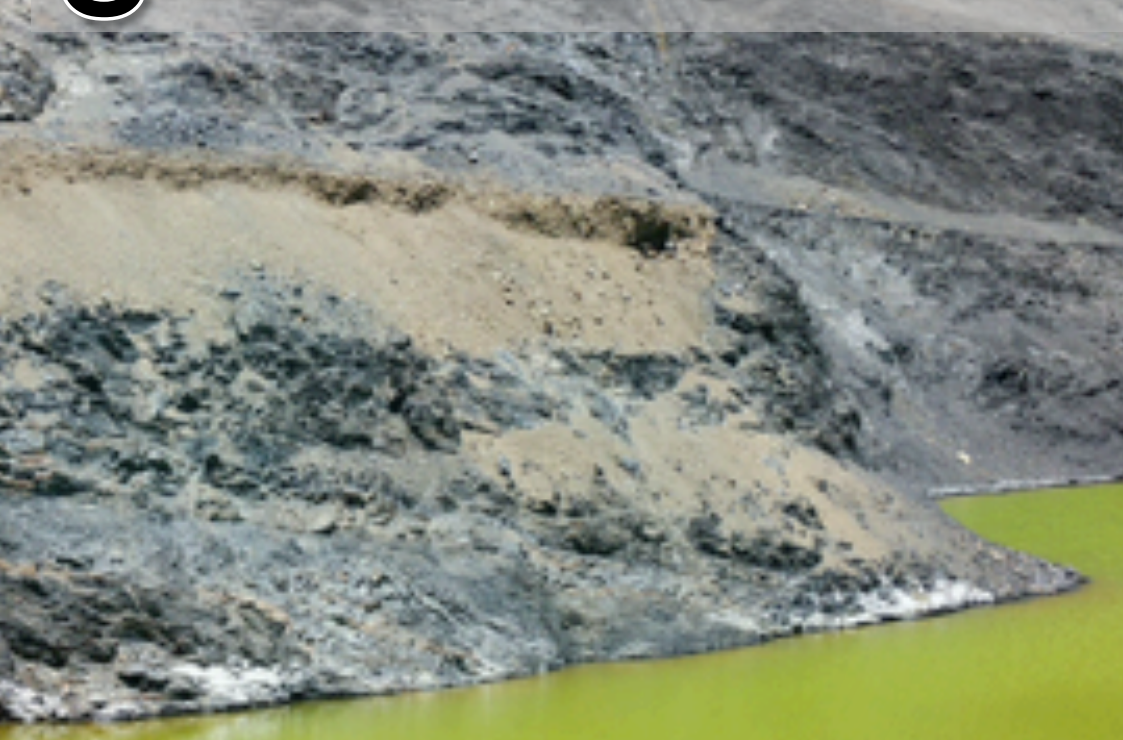

Connor Newman ${ }^{1}$ and Jeff Mann ${ }^{2}$ 'Nevada Division of Environmental Protection ${ }^{2}$ National Oilwell Varco

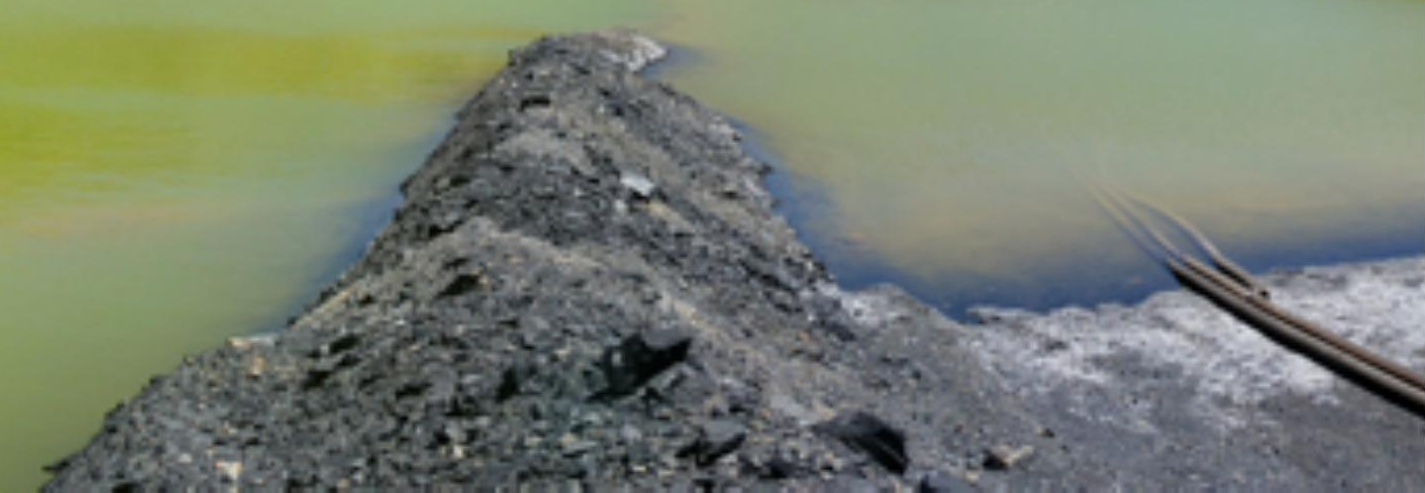




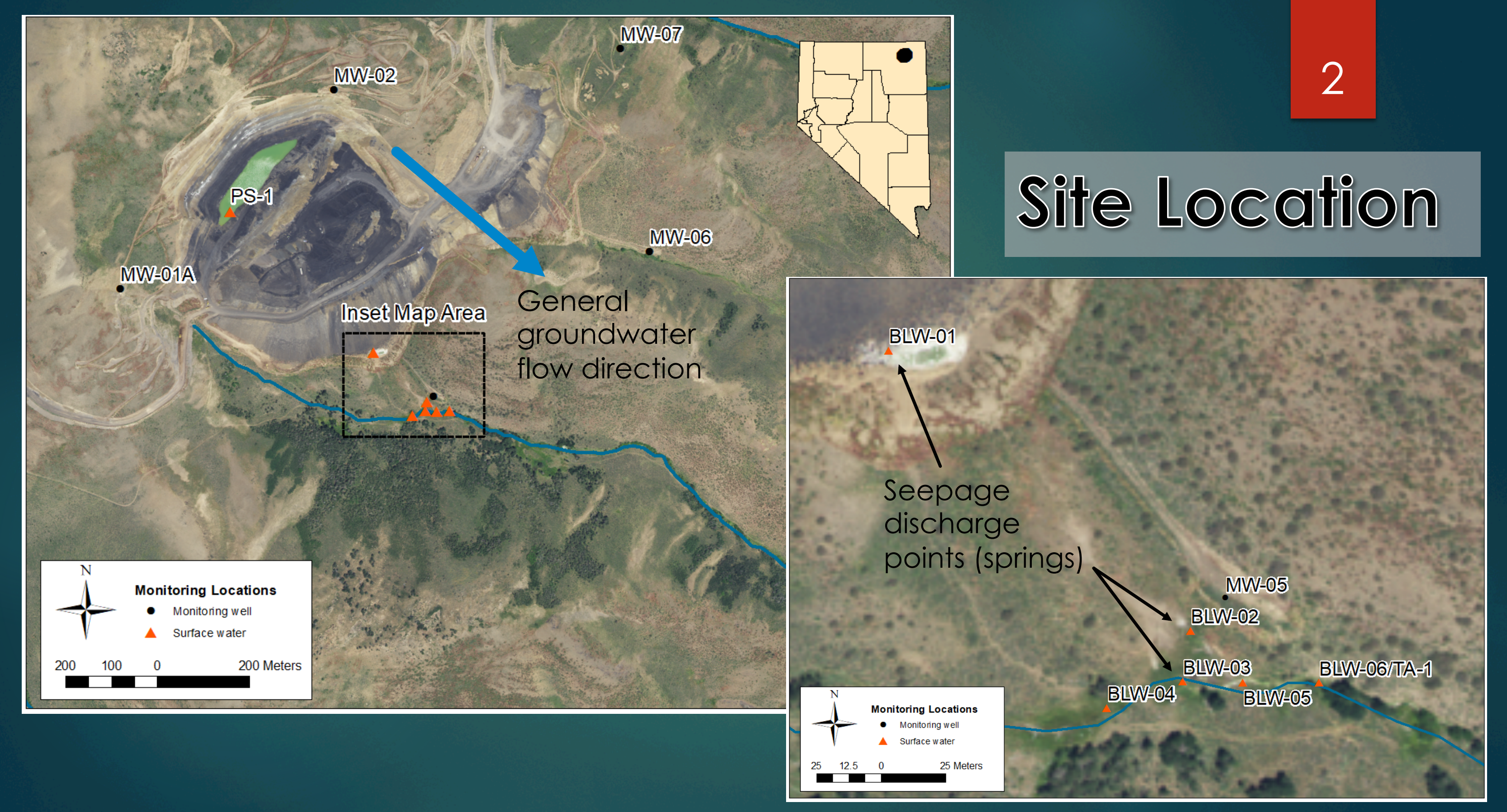




\section{Waste Rock Seepage}

\section{Seasonal streamflow}

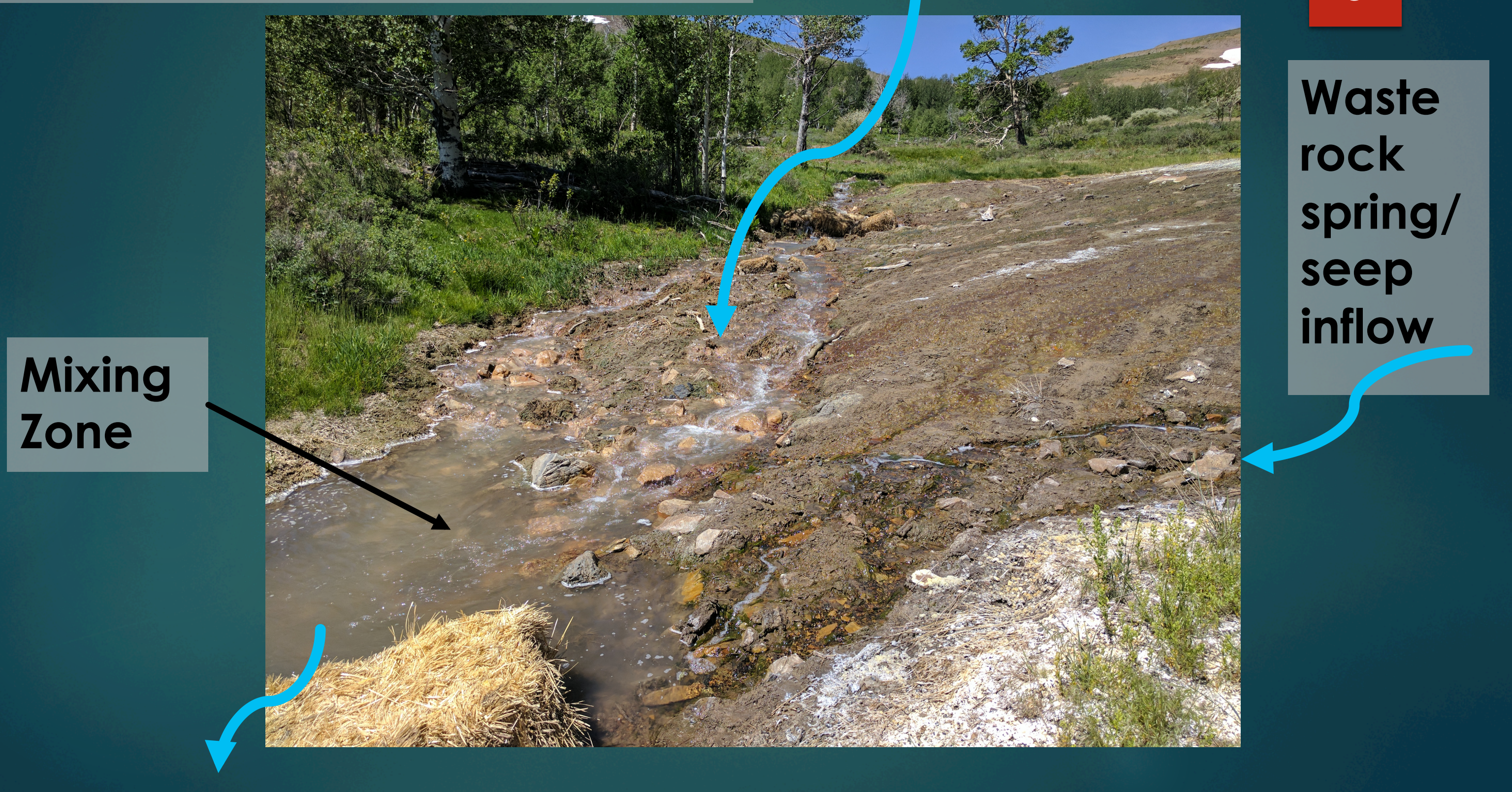




\section{Geochemical Characteristics}

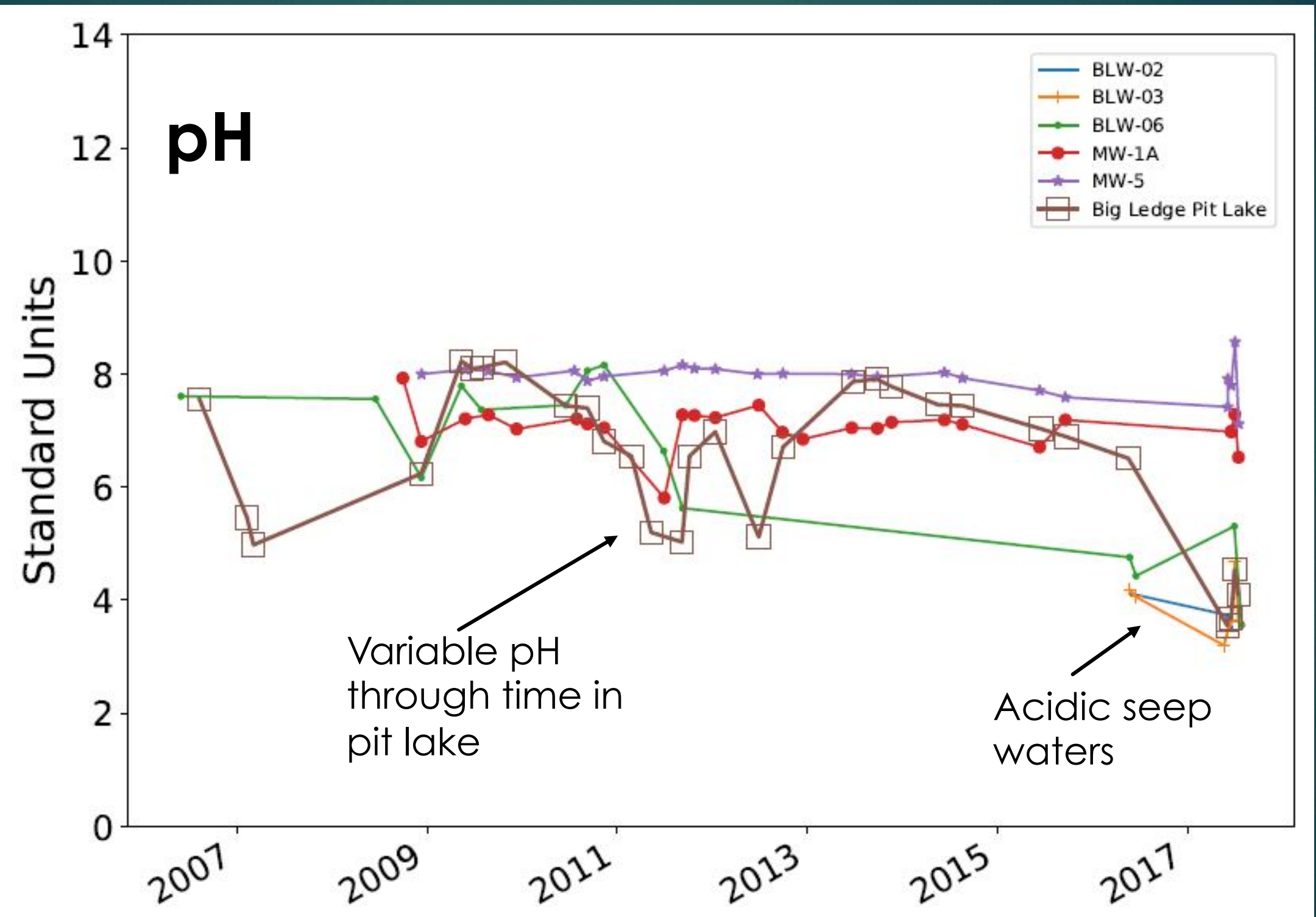




\section{Geochemical Characteristics}

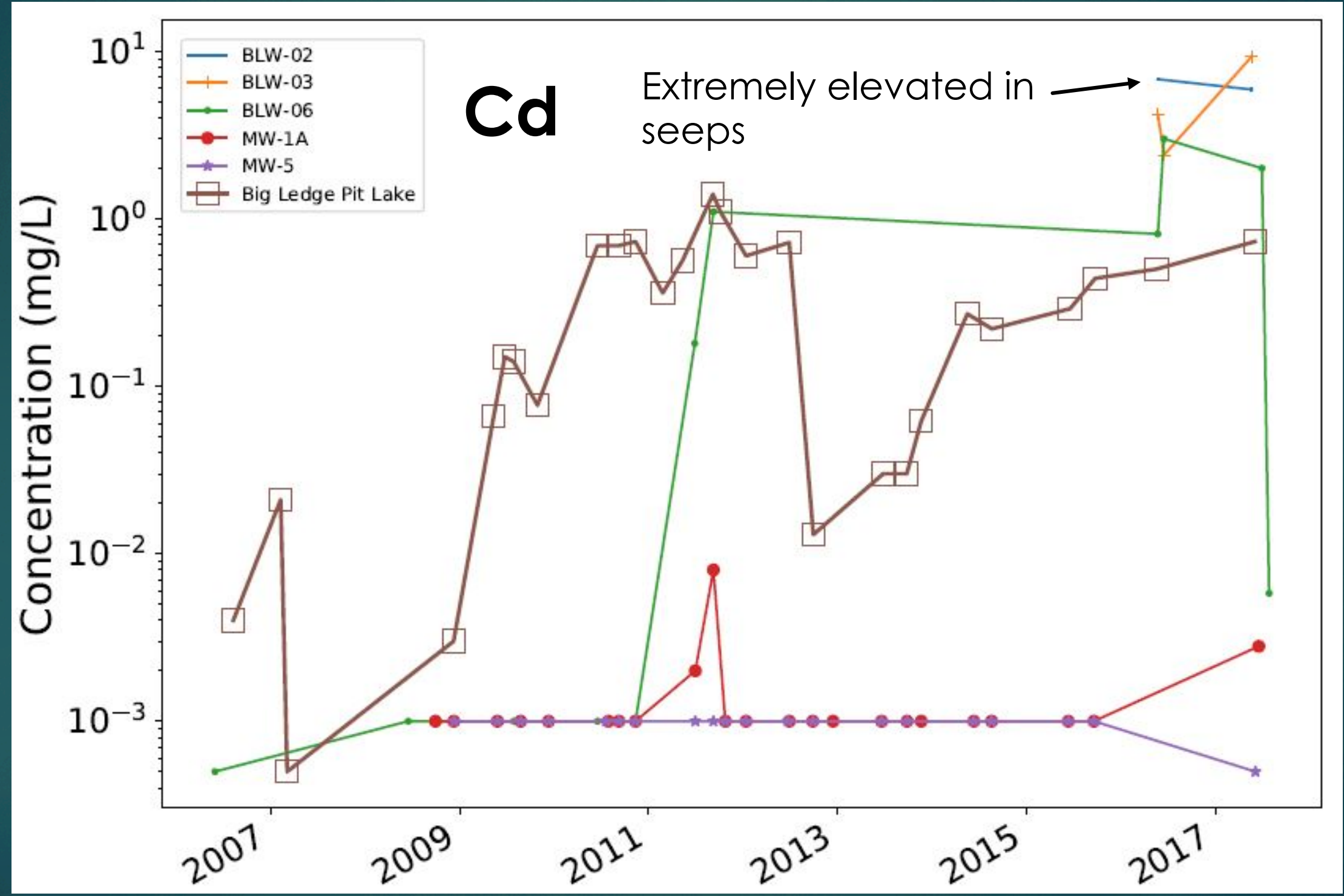




\section{Geochemical Characteristics}
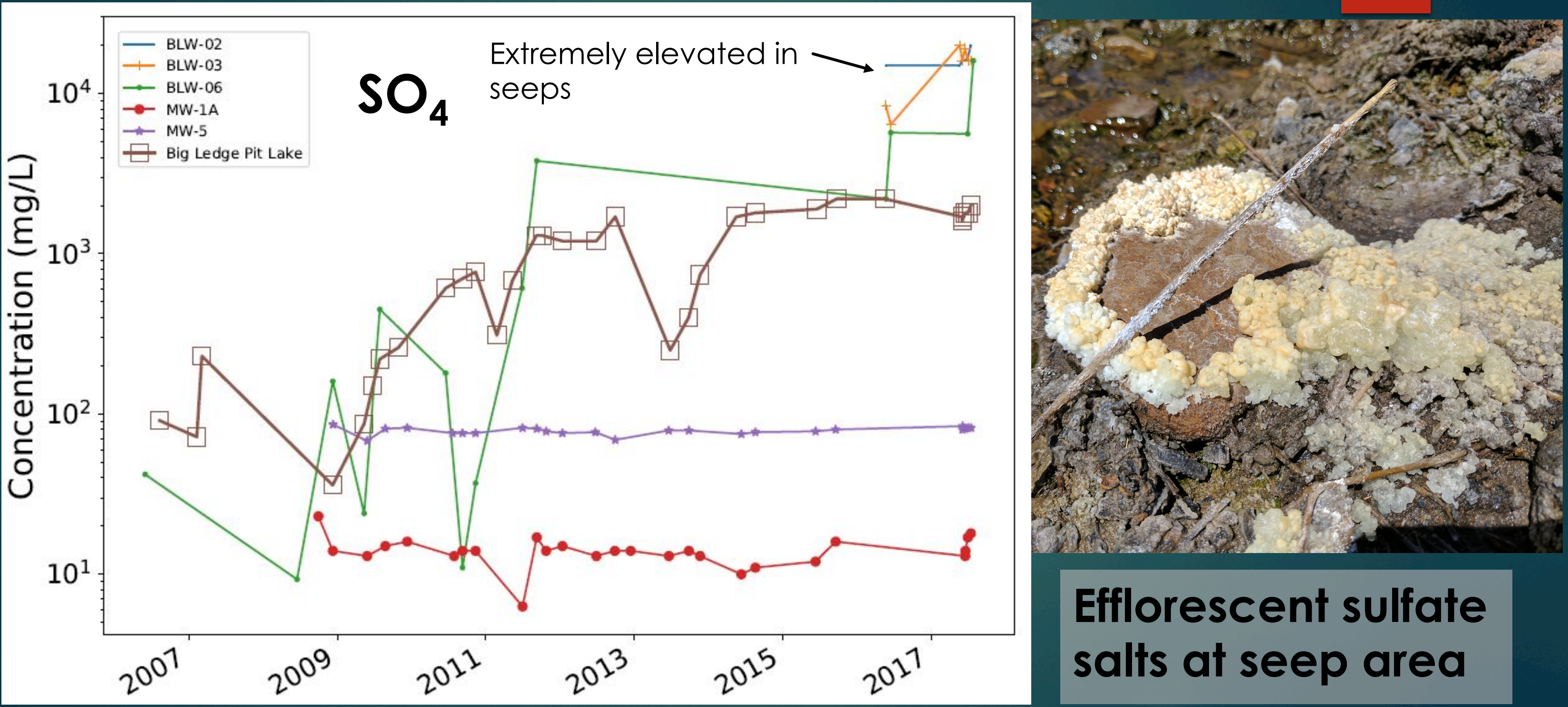

Efflorescent sulfate salts at seep area 


\section{Study Goals and Methods}

Evaluate pit-lake hydrology (flow-through or terminal)
Determine likely sources for water and solutes in the

Evaluate pit-lake hydrology (flow-through or terminal)
Determine likely sources for water and solutes in the seepage, and identify potential flow paths

Isotopic tracers $\left(\delta^{2} \mathrm{H}, \delta^{18} \mathrm{O}, \delta^{34} \mathrm{~S}\right)$

Mixing calculations and inverse geochemical modeling

Cross-correlations analysis

Evaluate potential management and closure options

$$
\text { (n) }
$$




\section{Water Isołope Results}

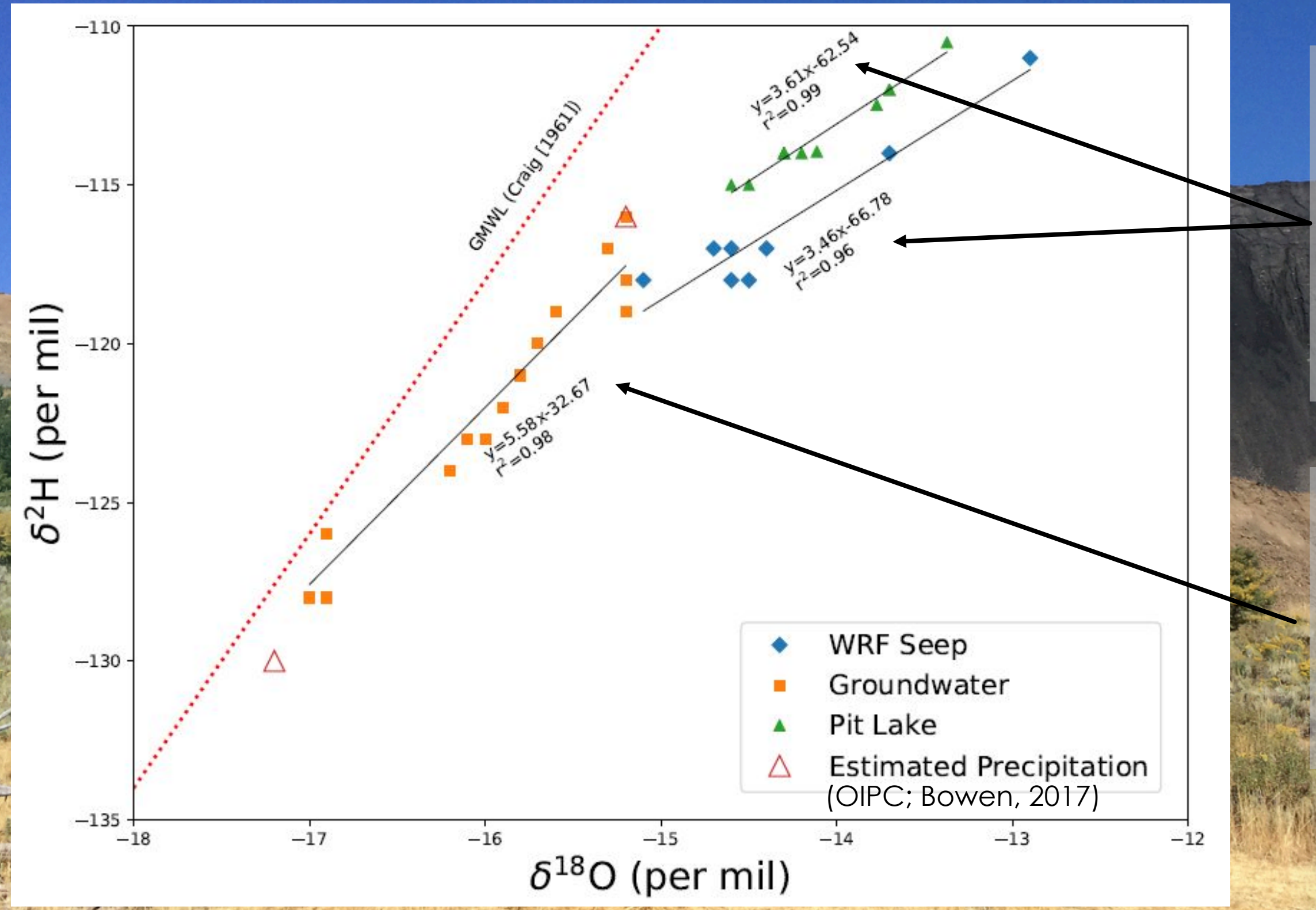

\section{Nearly equal} slopes for evaporation lines of pit lake and seeps

Groundwater representative of winter and spring recharge 


\section{Sulfur Isotope Results}
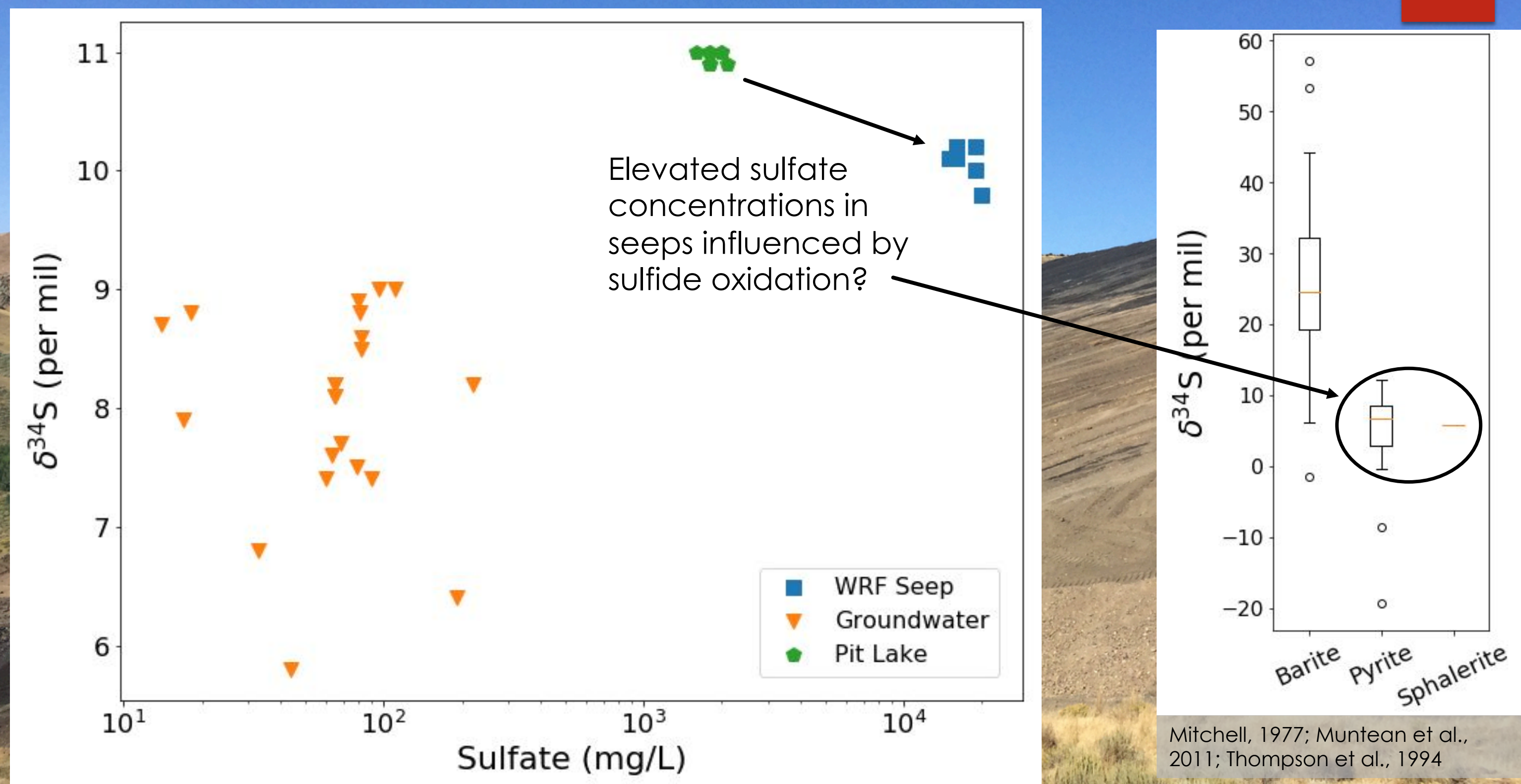

Mitchell, 1977; Muntean et al. 2011 ; Thompson et al., 1994 


\section{Isotope Mixing Calculations}

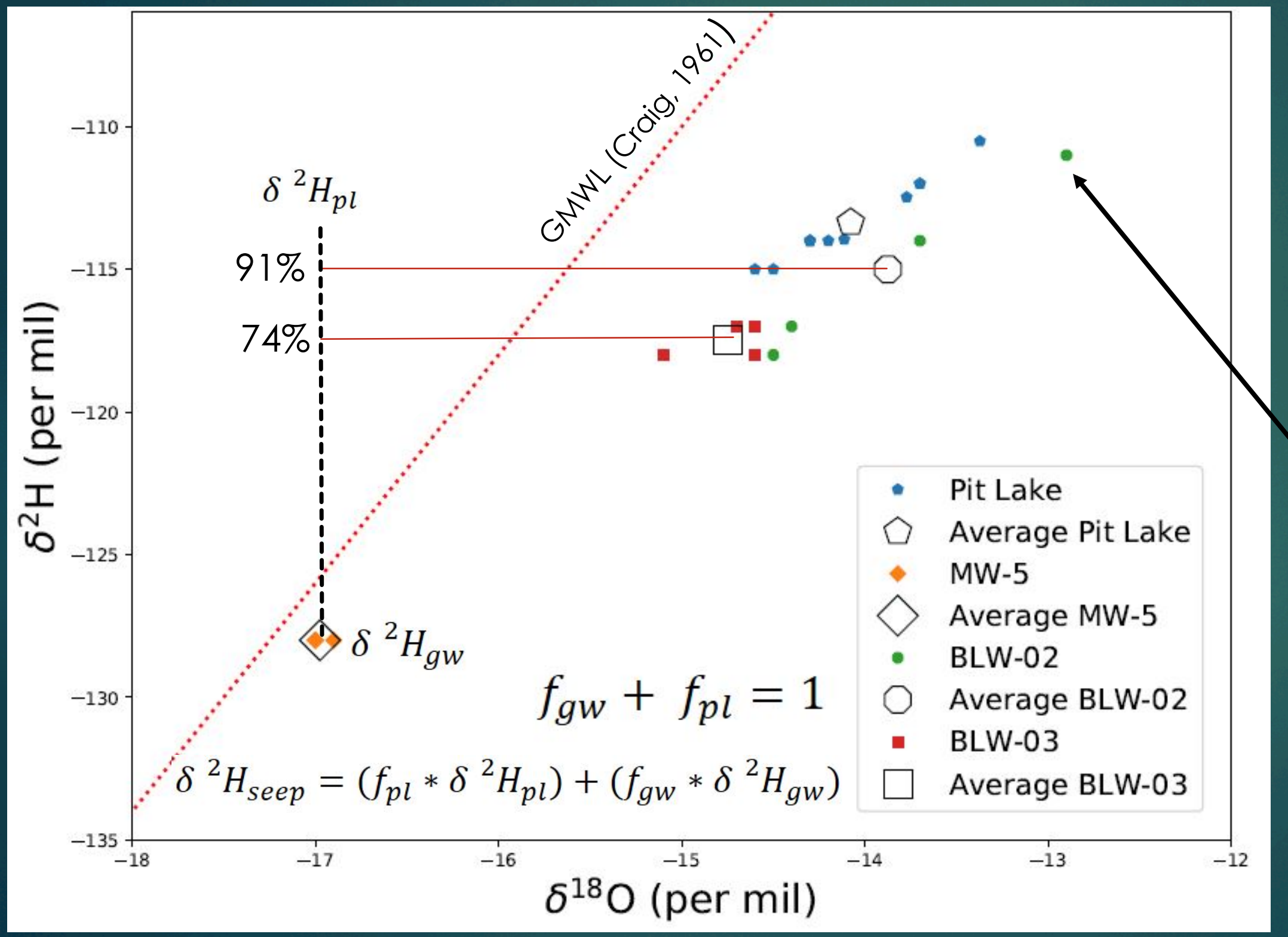

Using $\delta^{2} \mathrm{H}$ as a conservative tracer, results indicate that pit-lake outflow could make up $-74 \%-91 \%$ of seepage water

The composition of BLW-02 indicates ongoing evaporation or input of $\delta{ }^{18} \mathrm{O}$ from an unknown source

This does not account for other potential water sources on the site 


\section{Cross-Correlation}

A method to evaluate relationships between time-delayed datasets (e.g., Lee et al., 2006)

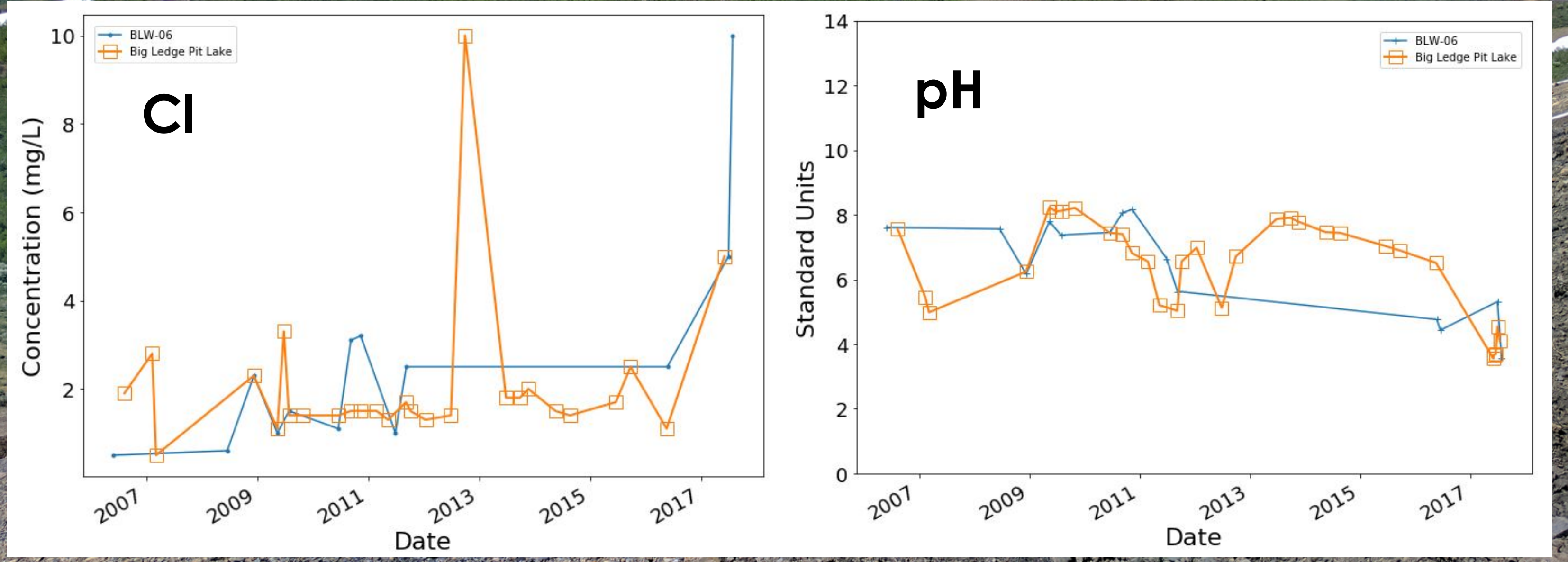




\section{Inverse Modeling}

\section{Groundwater}

(MW-3A or MW-5)

\section{Pit Lake}

Precipitation

Minerals

in WRF

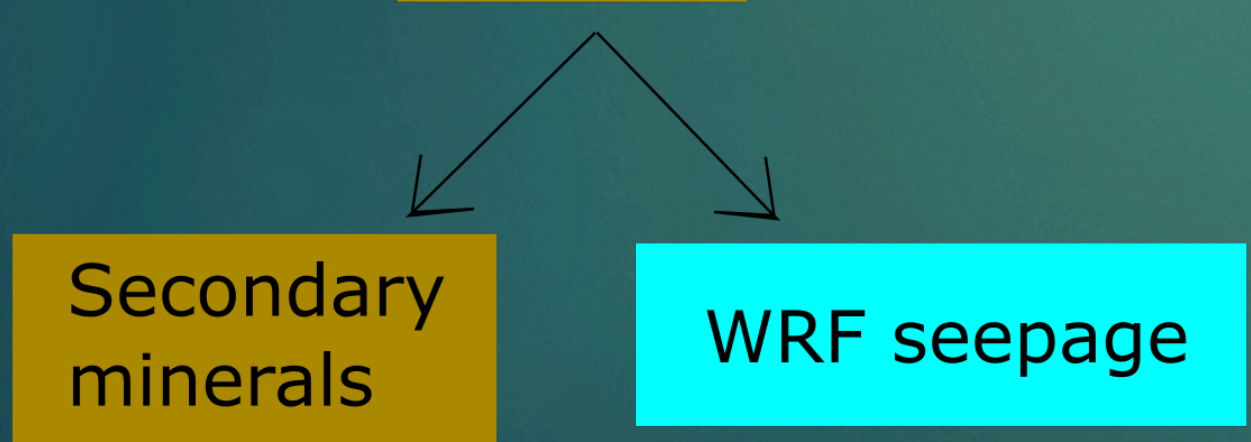

- Inverse modeling can indicate mixing relationships and potential mineral phases (e.g., Glynn and Brown, 2012)

- Various models were set up with different groundwater inputs and mineral equilibrium assumptions

- The inverse modeling would be made more robust by including isotopes, but data gaps exist 


\section{Inverse Modeling Results}

- A variety of inverse models are compatible with site observations

- All models include dissolution of sulfide minerals and precipitation of metal oxyhydroxides and salts

- The fraction of the pit lake is broadly similar to that calculated using isotope mixing

\begin{tabular}{|c|c|c|c|}
\hline $\begin{array}{c}\text { Minerals } \\
\text { Dissolved }\end{array}$ & $\begin{array}{c}\text { Minerals } \\
\text { Precipitated }\end{array}$ & $\begin{array}{c}\text { Minerals Either } \\
\text { Ppt. or Diss. }\end{array}$ & $\begin{array}{c}\text { Fraction of pit- } \\
\text { lake water in } \\
\text { seeps }\end{array}$ \\
\hline $\begin{array}{c}\text { Pyrite, } \\
\text { sphalerite, } \\
\text { fluorite, galena }\end{array}$ & $\begin{array}{c}\text { Manganite, } \\
\text { gypsum, } \\
\text { epsomite }\end{array}$ & $\begin{array}{c}\text { Melanterite, } \\
\text { ferrihydrite }\end{array}$ & $0.78-0.99$ \\
\hline
\end{tabular}




\section{Conclusions}

- The Big Ledge pit lake is a flow-through system, which discharges to surface water

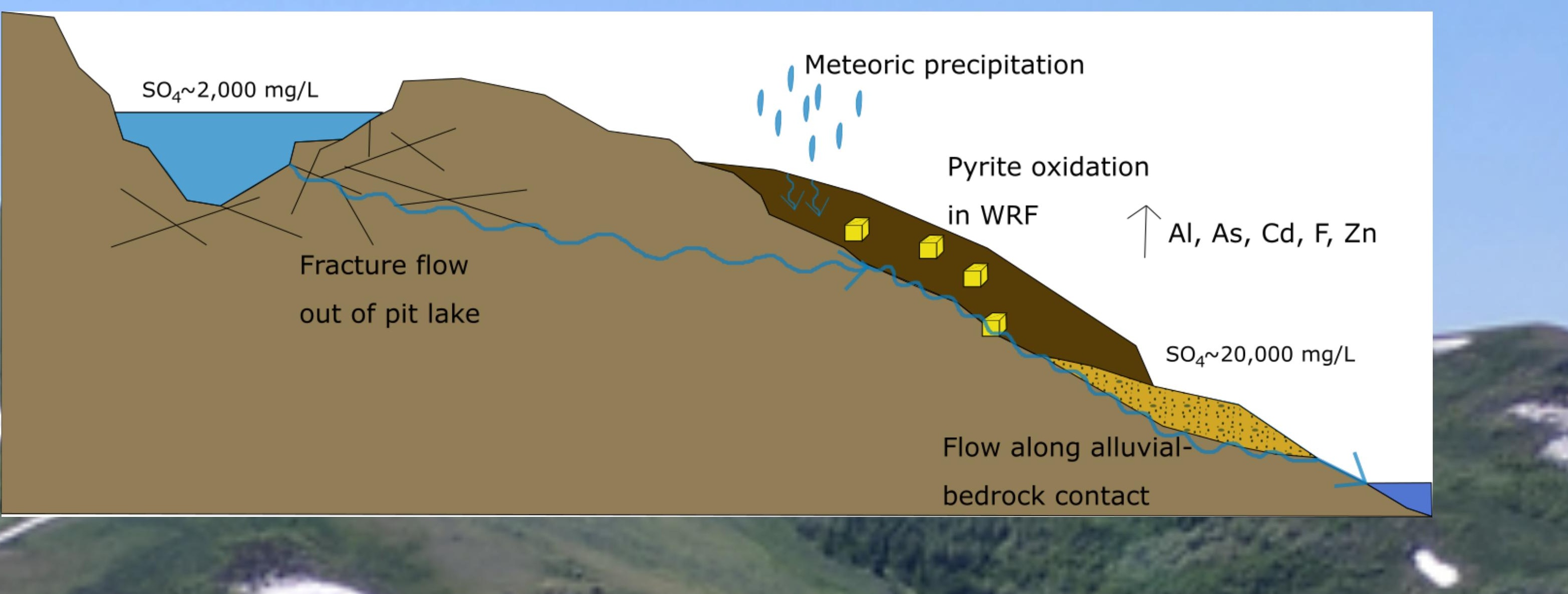




\section{Conclusions}

- The Big Ledge pit lake is a flow-through system, which discharges to surface water

- Multiple methods (isotope mixing and inverse geochemical modeling) indicate that pit-lake discharge makes up at least $-75 \%$ of waste rock seepage

- Mineral equilibrium (both dissolution and precipitation) is an important process in controlling the mass balance of seepage

- Groundwater flow in the area is likely fracture controlled based on the hydraulic gradient and statistical analysis of travel time

- Isotopes are a useful method to evaluate pit-lake hydrology, and hydrologic studies should utilize multiple methods 


\section{Potential Ongoing Work}

- Determine the isotopic composition of sulfate salts and sulfide minerals specific to the site

- Calibrate a groundwater-flow model to quantify the pit-lake water budget

- Utilize predictive geochemical modeling to evaluate different closure scenarios 


\section{Thank you!}

\section{Questions?}




\section{References}

Bowen, G. J., 2017, The Online Isotopes in Precipitation Calculator, version 3.1.

Glynn, P. and Brown, J., 2012, Integrating field observations and inverse and forward modeling: Application at a site with acidic, heavy-metal-contaminated groundwater, pp. 181-233, in: Bundschuh, J. and Zilberbrand, M., eds., Geochemical Modeling of Groundwater, Vadose, and Geothermal Systems, CRC Press.

Lee, L.J.E., Lawrence, D.S.L., and Price, M., 2006, Analysis of water-level response to rainfall and implications for recharge pathways in the Chalk aquifer, SE England, Journal of Hydrology, vol. 330, pp. 604-620, DOl: 10.1016/j.jhydrol.2006.04.025.

Mitchell, A.W., 1977, Geology of some bedded barite deposits, north central Nevada, Masters Thesis, University of Nevada, Reno, pp. 65.

Muntean, J. L., Cline, J. S., Simon, A. C., and Longo, A. A., 2011, Magmatic-hydrothermal origin of Nevada's Carlin-type gold deposits, Nature Geoscience, v. 4, pp. 122-127.

Thomson, B., Fallick, A.E., Boyce, A.J., and Rice, C., 1994, The Candelaria silver deposit, Nevada - preliminary sulphur, oxygen, and hydrogen isotope geochemistry, Mineralium Deposita, vol. 29, pp. 318-329. 